\title{
Three Decades of the Journal of Financial Counseling and Planning
}

\author{
Jing Jian Xiao, ${ }^{a} \odot$ Beatrix Lavigueur, ${ }^{b}$ Amanda Izenstark, ${ }^{c} \odot$ Sherman D. Hanna, ${ }^{d} \oplus$ and \\ Frances C. Lawrence ${ }^{e}$
}

This article describes the current status and trends in the past three decades (1990-2019) of the Journal of Financial Counseling and Planning (JFCP). Since its first issue published in 1990, JFCP has become a major research outlet in consumer finance. The journal publishes cutting-edge, peer-reviewed, original research papers on consumer financial counseling, planning, and education that have broad impacts on both academic research and business practices in the field of consumer finance. It is included in many major indexes such as Scopus, Emerging Source Citation Index, EconLit, among others. It has published influential papers on consumer financial well-being, financial capability, financial education, financial counseling, financial planning, retirement planning, risk tolerance, and financial behavior change.

Keywords: content analysis, financial counseling, financial education, financial planning, financial well-being, journal review

$\mathrm{T}$ The Journal of Financial Counseling and Planning $(J F C P)$ is the official research journal of the Association for Financial Counseling and Planning Education $\left(\mathrm{AFCPE}^{\mathrm{TM}}\right)$. Its mission is to publish original research to enrich the literature of consumer finance and provide implications for practitioners in public policymaking, business practices, and consumer education. Two papers described its contents and trends in its first decade (Hanna, 1999) and second decade (Ji, Hanna, Lawrence, \& Miller, 2010). This article describes the current status and trends of this journal over three decades, especially looking at the third decade (2010-2019). We also propose future directions for strengthening the journal as a major outlet in consumer finance research and practice.

\section{Background Information of JFCP}

Editors. The founding editor was Sherman D. Hanna (19902002), the second editor was Sandra Helmick (2003-2005), the third editor was Fran Lawrence (2006-2013), and the current editor is Jing Jian Xiao (2014-present).

\section{Book Editors}

Two people served as book review editors, Musaddak J. Alhabeeb (1997-2002) and Barbara O'Neill (2004-2015). Starting in 2016, JFCP stopped publishing book reviews to give more space for publishing original research papers.

\section{Associate Editors}

The following people served as associate editors in decades one or two: Sharon Burns (1990-1991), Suzanne Lindamood (1997-1998), William Bailey (1992-1997), and Rui Yao (2001-2002). Former associate editors in decade three were Sonya Britt-Lutter (2017-2018) and Joyce Serido (2017-2018). Current associate editors are Swarn Chatterjee (2017-present), Jr-Tsung Huang (2017present), Charlene M. Kalenkoski (2017-present), Jinhee Kim (2017-present), Yoon Lee (2019-present), and Tong

\footnotetext{
${ }^{a}$ JFCP Editor and Professor, Department of Human Development and Family Studies, University of Rhode Island, Kingston, RI 02881. E-mail: xiao@uri.edu. ${ }^{b}$ JFCP Editorial Assistant and Graduate student, Department of Human Development and Family Studies, University of Rhode Island, Kingston, RI 02881. E-mail: blavigueur@my.uri.edu.

${ }^{c}$ JFCP Editorial Board Member and Professor, Library, University of Rhode Island, Kingston, RI 02881.E-mail: amanda@uri.edu.

${ }^{d}$ JFCP Founding Editor and Professor, Department of Human Services, Ohio State University, 1787 Neil Ave., Columbus, OH 43210. E-mail: hanna.1@osu.edu.

${ }^{e}$ JFCP Former Editor, Professor and Chair, Department of Human Sciences, University of Missouri, 241 Stanley Hall, Columbia, MO 65211. E-mail: lawrencef@missouri.edu.
} 
Yu (2019-present). Associate editors help handle peer review processes, provide accept/revise/reject recommendations for the editor, and give suggestions for major decisions regarding the journal.

\section{Guest Editors}

published several special issues on selected topics and the following people served as guest editors (in parentheses are the topic and publication year): William H. Carter, Jonathan Fox, and Kate Padgett Walsh (Ethics, 2017), Manouchehr Mokhtari (Health, 2018), and Jr-Tsung Huang (Financial well-being, 2018). Several special issues are planned that will be published in future issues.

\section{Size Change}

The journal was originally published in a smaller size of paper $\left(6^{\prime \prime} \times 8.5^{\prime \prime}\right)$. Starting in 1995 , under the editorship of Sherman D. Hanna, the journal was published in a larger size of paper $\left(8.5^{\prime \prime} \times 11^{\prime \prime}\right)$.

\section{Issue Frequency Change}

Originally, only one issue of $J F C P$ was published per year. Starting in 1997, under the editorship of Sherman D. Hanna, two issues a year are published.

\section{Name Change}

The original name of the journal was Financial Counseling and Planning. In 2008 under the editorship of Fran Lawrence, the name was changed to Journal of Financial Counseling and Planning in volume 19 issue 2.

\section{Change of Publisher}

From its beginning year (1990) to 2015, the journal was selfpublished by AFCPE. Starting in 2016, under the editorship of Jing Jian Xiao, the journal has been published by Springer Publishing Company.

\section{Number of Papers Published}

During the first two decades (1990-2009), JFCP published 271 papers and 47 book or software reviews (Ji et al., 2010). During the third decade (2010-2019), 168 research papers, 8 editorials, and 35 book reviews were published. In the following sections, only statistics of research papers are presented.

\section{Authorships \\ Prolific Authors}

During the third decade, the most prolific author published in $J F C P$ was Sherman D. Hanna. Other prolific authors included Sonya Britt-Lutter and Swarn Chatterjee (both ranked second); John E. Grable, Michael Finke, Sandra J. Huston, and Kyoung Tae Kim (all ranked fourth; Table 1, left panel). For comparison, John Grable and Sherman D. Hanna were in the top five prolific authors in decade two (Ji et al., 2010) and Sherman D. Hanna was the most prolific author during the first decade (Hanna, 1999). For all three decades, the top five prolific authors were Sherman D, Hanna, John E. Grable, Jing Jian Xiao, Sharon A. DeVaney, and Jean M. Lown (Table 1, right panel).

\section{Sole Versus Coauthorship}

coauthorship. The percentage of sole authorship was similar to decade two but much lower than decade one, which was $16 \%$, compared to $17 \%$ in decade two and $30 \%$ in decade one (Table 2).

\section{Author Affiliations}

Based on Scopus, in decade three, the following universities have the highest numbers of authors appearing in JFCP: Kansas State University, University of Georgia, Texas Tech University, and Ohio State University. University of Georgia, and Ohio State University were also on the top three lists of author affiliations during decades one and two (Table 3).

\section{Author Countries}

The author base has greatly expanded internationally over the last three decades. Based on Scopus, in the first decade, authors were only from four countries (United States, Canada, South Korea, and Kenya). In the second decade, authors were from 10 countries (United States, South Korea, Australia, Canada, Germany, Greece, New Zealand, Poland, Russian Federation, and Sweden). In the third decade, authors were from 20 countries/areas (United States, China, South Korea, Australia, Canada, Sweden, Taiwan, Hong Kong, New Zealand, South Africa, Turkey, United Kingdom, Belgium, Brazil, India, Italy, Japan, Kazakhstan, Lebanon, and Malaysia; Table 4).

\section{Contents and Methods}

\section{Keywords}

Keyword changes usually demonstrate the trends of the journal. In this journal, keywords are defined and 
TABLE 1. Most Prolific Authors During 2010-2019 and 1990-2019

\begin{tabular}{|c|c|c|c|c|c|}
\hline \multirow[b]{2}{*}{ Rank } & \multicolumn{3}{|c|}{ Decade Three (2010-2019) } & \multicolumn{2}{|c|}{ Three Decades (1990-2019) } \\
\hline & Author & Pub. No. & Rank & Author & Pub. No. \\
\hline$\overline{1}$ & Sherman D. Hanna & 9 & 1 & Sherman D. Hanna & 29 \\
\hline 2 & Swarn Chatterjee & 6 & 2 & John E. Grable & 15 \\
\hline 2 & Sonya Britt-Lutter & 6 & 2 & Jing Jian Xiao & 15 \\
\hline 4 & John E. Grable & 5 & 4 & Sharon A. DeVaney & 13 \\
\hline 4 & Michael Finke & 5 & 5 & Jean M. Lown & 12 \\
\hline 4 & Sandra J. Huston & 5 & 6 & Sharon M. Danes & 10 \\
\hline 4 & Kyoung Tae Kim & 5 & 6 & Jinhee Kim & 10 \\
\hline 8 & Jean M. Lown & 4 & 8 & Swarn Chatterjee & 7 \\
\hline 8 & Martin Seay & 4 & 8 & Thomas Garman & 7 \\
\hline 8 & Kristy Archuleta & 4 & 8 & Michael Gutter & 7 \\
\hline 8 & Sharon M. Danes & 4 & 8 & Sandra Huston & 7 \\
\hline 8 & Patti J. Fisher & 4 & 8 & Barbara O’Neill & 7 \\
\hline 8 & Russell N. James III & 4 & 8 & Deanna L. Sharpe & 7 \\
\hline 8 & Jinhee Kim & 4 & & & \\
\hline
\end{tabular}

Note. Data are collected from Scopus. For most prolific authors in 1990-1999, see Hanna (1999) and in 2000-2009, see Ji et al. (2010).

TABLE 2. Single Author Versus Coauthors by Decade

\begin{tabular}{|c|c|c|c|}
\hline \multirow[b]{2}{*}{ Authorship } & Decade One (1990-1999) & Decade Two (2000-2009) & Decade Three (2010-2019) \\
\hline & Percentage & Percentage & Percentage \\
\hline Single author & 30 & 24 & 28 \\
\hline Coauthors & 70 & 117 & 140 \\
\hline Article \# & 130 & 141 & 168 \\
\hline
\end{tabular}

Source: For decades one and two, information is from Ji et al. (2010). Information for decade three is calculated by authors.

TABLE 3. Top Five Author Affiliations by Decade

\begin{tabular}{|c|c|c|c|c|c|c|c|c|}
\hline \multirow{2}{*}{\multicolumn{2}{|c|}{$\begin{array}{l}\text { Decade One (1990-1999) } \\
\text { Rank Affiliation }\end{array}$}} & \multicolumn{3}{|c|}{ Decade Two (2000-2009) } & \multicolumn{4}{|c|}{ Decade Three (2010-2019) } \\
\hline & & \multicolumn{3}{|c|}{ Pub. No. Rank Affiliation } & \multicolumn{3}{|c|}{ Pub. No. Rank Affiliation } & \multirow{2}{*}{$\frac{\text { Pub. No. }}{22}$} \\
\hline 1 & Ohio State University & 23 & 1 & University of Georgia & 15 & 1 & Kansas State University & \\
\hline & Purdue University & 14 & 2 & Ohio State University & 14 & 2 & University of Georgia & 20 \\
\hline 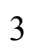 & University of Georgia & 10 & 3 & Texas Tech University & 12 & 3 & Texas Tech University & 17 \\
\hline$T$ & University of Missouri & 9 & 4 & Virginia Tech & 11 & 4 & Ohio State University & 12 \\
\hline 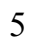 & Kansas State University & 7 & 4 & Purdue University & 11 & 5 & University of Alabama & 9 \\
\hline & University of Rhode Island & 7 & 6 & Utah State University & 10 & 5 & Virginia Tech & 9 \\
\hline & Virginia Tech & 7 & 7 & University of Missouri & 9 & 6 & Utah State University & 7 \\
\hline & & & 7 & Kansas State University & 9 & 6 & University of Minnesota & 7 \\
\hline
\end{tabular}

Source: Scopus and author calculations. 
TABLE 4. Author Countries/Areas by Decade

\begin{tabular}{llllll}
\hline Decade One (1990-1999) & Pub. No. & Decade Two (2000-2009) & Pub. No. & Decade Three (2010-2019) & Pub. No. \\
\hline United States & 123 & United States & 135 & United States & 149 \\
Canada & 3 & South Korea & 3 & China & 6 \\
South Korea & 2 & Australia & 2 & South Korea & 4 \\
Kenya & 1 & Canada & 1 & Australia & 3 \\
& & Germany & 1 & Canada & 3 \\
& Greece & 1 & Sweden & 3 \\
& New Zealand & 1 & Taiwan & 3 \\
& Poland & 1 & Hong Kong & 2 \\
& Russia & 1 & New Zealand & 2 \\
& Sweden & 1 & South Africa & 2 \\
& & & Turkey & 2 \\
& & & United Kingdom & 2 \\
& & & Belgium & 1 \\
& & & Brazil & 1 \\
& & & India & 1 \\
& & & Italy & 1 \\
& & & Japan & 1 \\
& & & Kazakhstan & 1 \\
& & & Malaysia & 1 \\
& & & & 1 \\
& & & &
\end{tabular}

Source: Scopus and author calculation.

provided by authors to describe the subjects of articles. For decade three, we analyzed keyword frequency using Scopus and compared these with keywords used in decade one and decade two presented by $\mathrm{Ji}$ et al. (2010). We grouped keywords into thematic categories. The top six most used keywords for the third decade are financial literacy (which also includes financial knowledge, appearing 44 times), retirement planning (retirement, retirement saving, retirement adequacy, 35), risk tolerance (financial risk tolerance, risk aversion, risk, 32), financial planning (financial advice, financial planner, estate planning, 31), financial education (adult education, workplace education, employee education, education, 29), and personal financial behavior (financial behavior, 22; Table 5). Compared to the last two decades, three categories, financial education, financial literacy, and personal financial behavior were not ranked in the first decade but ranked 7th, 3rd, and 5th, respectively, in the second decade. In decade three, the ranking of retirement planning increased (2nd vs. 3rd and 11th), that of financial planning increased from decade two (4th vs. 3rd and 7th), and that of risk tolerance decreased from decade two (3rd vs. 6th and 2nd).

Besides the keywords presented in Table 5, other commonly used keywords in the last 30 years were financial well-being (which also includes financial wellness, financial satisfaction, economic well-being, appearing 32 times in Scopus), financial stress (stress, economic stress, financial stress, financial problems, financial anxiety, 30), college student (young adult, emerging adult, 21), gender (gender difference, 16), and financial socialization (economic socialization, 12).

\section{Research Method Type}

Following Ji et al. (2010), among research papers, there are four types of research methods including qualitative research, quantitative research, normative research, and literature review or opinion. In decade three, the percentage of qualitative research papers among 168 papers was $84 \%$, increasing from the previous decades $(70 \%$ and $69 \%$, respectively). Among other types, percentages of qualitative 
TABLE 5. Top Keywords Used by Decade

\begin{tabular}{lllllll}
\hline & \multicolumn{2}{c}{$\mathbf{1 9 9 0}-\mathbf{1 9 9 9}$} & \multicolumn{2}{c}{$\mathbf{2 0 0 0}-\mathbf{2 0 0 9}$} & \multicolumn{2}{c}{$\mathbf{2 0 1 0}-\mathbf{2 0 1 9}$} \\
\cline { 2 - 7 } Research Method & $\boldsymbol{n}$ & $\mathbf{R a n k}$ & $\boldsymbol{n}$ & $\mathbf{R a n k}$ & $\boldsymbol{N}$ & Rank \\
\hline Financial literacy & 0 & $\mathrm{n} / \mathrm{a}$ & 8 & 7 & 44 & 1 \\
Retirement planning & 14 & 3 & 7 & 11 & 35 & 2 \\
Risk tolerance & 11 & 6 & 14 & 2 & 32 & 3 \\
Financial planning & 14 & 3 & 8 & 7 & 31 & 4 \\
Financial education & 0 & $\mathrm{n} / \mathrm{a}$ & 12 & 3 & 29 & 5 \\
Personal financial behavior & 0 & $\mathrm{n} / \mathrm{a}$ & 11 & 5 & 22 & 6 \\
Credit & 12 & 5 & 8 & 7 & 16 & 7 \\
Saving & 19 & 2 & 5 & 12 & 14 & 8 \\
Financial management & 0 & $\mathrm{n} / \mathrm{a}$ & 11 & 5 & 12 & 9 \\
Investment & 11 & 6 & 12 & 3 & 10 & 10 \\
Financial counseling & 11 & 6 & 8 & 7 & 8 & 11 \\
Economic model & 11 & 6 & 1 & 14 & 0 & $\mathrm{n} / \mathrm{a}$ \\
Financial ratios & 11 & 6 & 3 & 13 & 0 & $\mathrm{n} / \mathrm{a}$ \\
Survey of consumer finances & 38 & 1 & 25 & 1 & 0 & $\mathrm{n} / \mathrm{a}$ \\
\hline Source:
\end{tabular}

Source: Information about keywords in decades one and two is from Ji et al. (2010). Information in decade three is from Scopus and author calculations.

TABLE 6. Research Methods by Decade

\begin{tabular}{|c|c|c|c|c|c|c|}
\hline \multirow{3}{*}{$\frac{\text { Research Method }}{\text { Qualitative method }}$} & \multicolumn{2}{|c|}{ 1990-1999 } & \multicolumn{2}{|c|}{ 2000-2009 } & \multicolumn{2}{|c|}{ 2010-2019 } \\
\hline & \multicolumn{2}{|c|}{ Percentage } & \multicolumn{2}{|c|}{ Percentage } & \multicolumn{2}{|c|}{ Percentage } \\
\hline & 3 & 2 & 14 & 10 & 8 & 5 \\
\hline Quantitative method & 91 & 70 & 97 & 69 & 142 & 84 \\
\hline Normative research & 22 & 17 & 14 & 10 & 5 & 3 \\
\hline Review and/or opinion & 14 & 11 & 16 & 11 & 14 & 8 \\
\hline Article \# & 130 & & 141 & & 168 & \\
\hline
\end{tabular}

Note. Information for the first two decades (1990-1999, 2000-2009) is from Ji et al. (2010). Information for the third decade (2010-2019) is calculated by the authors.

research, normative research, and review/opinion papers were $5 \%, 3 \%$, and $8 \%$, respectively, decreasing from the previous decade $(10 \%, 10 \%$, and $11 \%$, respectively; Table 6).

\section{Data Analysis Type}

Data analysis types include descriptive statistics, regression or regression-like analyses, and other analyses. According to $\mathrm{Ji}$ et al. (2010), descriptive statistics include univariate and bivariate analyses such as $t$ tests or chi-squared tests. Regression and regression-like analyses include ordinary least squares, probit, Tobit, logit, and other regression analyses. Other analyses include those that did not use descriptive and regression analyses such as factor analysis, path analysis, structural equation modeling, and so forth. During the third decade, the most used data analysis method, includes regression and regression-like analyses which accounted for $77 \%$ of all quantitative research papers, increased compared to decades one and two (69\% and 74\%, respectively). The percentage of papers using descriptive analyses was $8 \%$, decreased from decades one and two $(16 \%$ and $13 \%$, respectively). The percentage of quantitative papers using other types of analyses was $14 \%$, similar to the previous two decades (14\% and $13 \%$, respectively; Table 7 ).

\section{National or International Datasets Used}

During the third decade, 62 quantitative papers used national or international datasets. Among those, the most used dataset was Survey of Consumer Finance (SCF; 29\%), decreased from decades one and two $(76 \%$ and $58 \%$, 
TABLE 7. Data Analysis Type by Decade

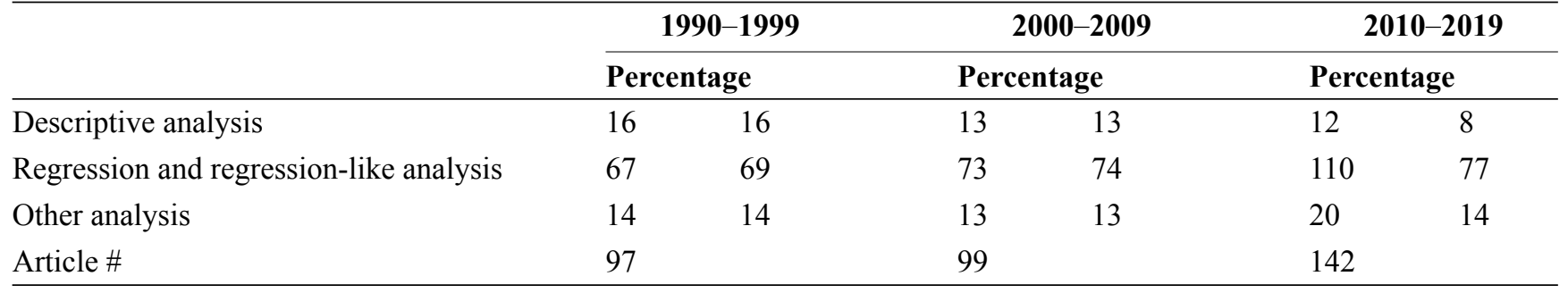

Note. Information for the first two decades (1990-1999, 2000-2009) is from Ji et al. (2010). Information for the third decade (2010-2019) is calculated by the authors.

respectively). However, $15 \%$ of the papers used the National Financial Capability Study (NFCS), which was not used in previous decades (NFCS started its first survey in 2009). Other popular datasets used in decade three were the Health and Retirement Study (HRS; 11\%) and National Longitudinal Surveys of Youth (NLSY; 11\%), increased from previous decades. One dataset, Consumer Expenditure Survey, was used in only one paper (2\%), lower than decade one $(8 \%)$ and similar to decade two $(2 \%)$. In addition, two datasets used in decade three were never used in previous decades, the Panel Study of Income Dynamics (PSID; 8\%), and De Nederlandsche Bank Household Survey (DNBHS; 5\%). The percentage of using other datasets was $21 \%$, increased from the previous two decades $(12 \%$ and $18 \%$, respectively). These national or international datasets were used for the first time in papers of this journal. Among them, international datasets included China Family Panel Study, Canadian General Social Survey, Household, Income, and Labor Dynamics in Australia, Organisation for Economic Co-operation and Development's (OECD) Programme for International Student Assessment; and U.S. national datasets included American Dream Demonstration, Asset and Health Dynamics among the Oldest Old, Familial Response to Financial Instability Study, Health Tracking Household Survey, National Longitudinal Study of Adolescent Health, National Survey of Midlife Development, Public Access to Court Electronic Records, and Survey of Income and Program Participation (Table 8).

\section{Citations}

Over the last three decades, $J F C P$ has experienced an increase in citations. Based on the report of Etkin (2020) of our publisher, Springer Publishing Company, citations of JFCP in journals listed in Web of Science (WOS) has increased in recent years (Figure 1). He also reported the top 10 journals that cited JFCP are JFCP (self-cited), Journal of Family and Economic Issues, Journal of Consumer
Affairs, Family and Consumer Science Research Journal, International Journal of Bank Marketing, International Journal of Consumer Studies, Children and Youth Services Review, Journal of Economic Education, Journal of Behavioral and Experimental Finance, and Journal of Economic Behavior \& Organization. Top 10 WOS categories that cited JFCP include economics, business, family studies, business-finance, education-education research, social work, social science-interdisciplinary, psychology-developmental, management, psychology-multidisciplinary. Top 10 countries that cited JFCP are the United States, Malaysia etc.

According to Scopus, in 2018 JFCP had a CiteScore of 1.65 and ranked 67/250 in finance and 175/592 in economics and econometrics. Based on Scopus, the 10 most cited papers published in JFCP are presented in Table 9, in which the topics covered were the financial well-being scale, financial education and behavior, gender difference in investing, risk tolerance, multiple imputation of SCF data, financial knowledge and behavior, compulsive buying scale, financial socialization, and teen financial knowledge and behavior.

\section{Indexing}

Over the last decade, the number of places where researchers can learn what articles have been published in JFCP has grown significantly. According to the 47th edition of Ulrich's Periodical Directory (2009), JFCP was indexed in five indexing services: Business Periodicals Index, Business Education Index, Journal of Economic Literature, PsycINFO, and Social Services Abstracts. In Ulrich's 57th edition (2019), which is the most current as of the writing of this article, JFCP is covered in 44 indexing services. Among these are successors to those listed in the 2009 edition, as well as newer sources such as EBSCO's Academic Search suite, ProQuest's ABI/INFORM, EconLit, 
TABLE 8. National Datasets Used by Decade

\begin{tabular}{|c|c|c|c|c|c|c|}
\hline \multirow{3}{*}{$\frac{\text { Datasets }}{\text { SCF }}$} & \multicolumn{2}{|c|}{ 1990-1999 } & \multicolumn{2}{|c|}{ 2000-2009 } & \multicolumn{2}{|c|}{ 2010-2019 } \\
\hline & \multicolumn{2}{|c|}{ Percentage } & \multicolumn{2}{|c|}{ Percentage } & \multicolumn{2}{|c|}{ Percentage } \\
\hline & 38 & 76 & 28 & 58 & 18 & 29 \\
\hline NFBS & $\mathrm{n} / \mathrm{a}$ & & 3 & 6 & $\mathrm{n} / \mathrm{a}$ & \\
\hline $\mathrm{RCS}$ & $\mathrm{n} / \mathrm{a}$ & & 3 & 6 & $\mathrm{n} / \mathrm{a}$ & \\
\hline CES & 3 & 6 & 1 & 2 & 1 & 2 \\
\hline HRS & $\mathrm{n} / \mathrm{a}$ & & 1 & 2 & 7 & 11 \\
\hline NLSY & 1 & 2 & 3 & 6 & 7 & 11 \\
\hline NLTCS & 2 & 4 & $\mathrm{n} / \mathrm{a}$ & & $\mathrm{n} / \mathrm{a}$ & \\
\hline DNBHS & $\mathrm{n} / \mathrm{a}$ & & $\mathrm{n} / \mathrm{a}$ & & 3 & 5 \\
\hline NFCS & $\mathrm{n} / \mathrm{a}$ & & $\mathrm{n} / \mathrm{a}$ & & 9 & 15 \\
\hline PSID & $\mathrm{n} / \mathrm{a}$ & & $\mathrm{n} / \mathrm{a}$ & & 5 & 8 \\
\hline Other & 6 & 12 & 9 & 18 & 12 & 19 \\
\hline Total & 50 & & 48 & & 62 & \\
\hline
\end{tabular}

Note. Information for the first two decades (1990-1999, 2000-2009) is from Ji et al. (2020). Information for the third decade (2010-2019) is calculated by the authors. CES = Consumer Expenditure Surveys; DNBHS = De Nederlandsche Bank Household Survey; HRS = Health and Retirement Study; NFBS = National Family Business Survey; NFCS = National Financial Capability Study; NLSY = National Longitudinal Surveys of Youth; NLTCS = National Long Term Care Survey; PSID = Panel Study of Income Dynamics; RCS = Retirement Confidence Survey; SCF = Survey of Consumer Finances.

\section{Figure 1. JFCP citations in Web of Science Journals}

Sum of Times Cited per Year

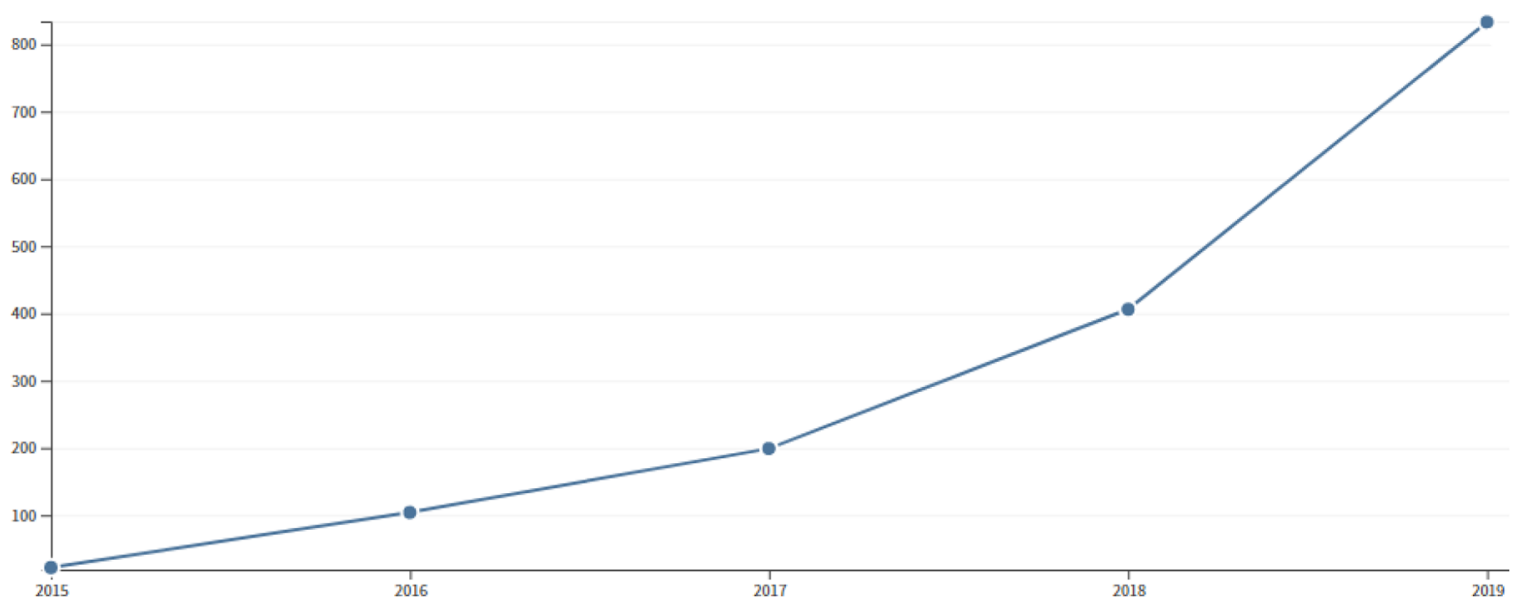

Source: Etkin (2020).

ERIC, and Scopus. JFCP is also indexed by Google Scholar, which has become a primary scholarly literature search tool for many researchers. These increases provide authors publishing with the journal enhanced discoverability with the potential for increased citations in the future.
The journal was accepted in September of 2018 for inclusion in the Clarivate Analytics (formerly Thomson Reuters) Emerging Sources Citations Index (ESCI). This is the first step toward getting an Impact Factor for the Journal and being included in the Social Science Citation Index (SSCI; 
TABLE 9. Most Cited Articles on Scopus over Three Decades (1990-2019)

\begin{tabular}{|c|c|c|}
\hline Rank & Citation & Citation \# \\
\hline 1 & $\begin{array}{l}\text { Prawitz, A. D., Garman, E.T., Sorhaindo, B., O’Neill, B., Kim, J., } \\
\text { \& Drentea, P. (2006). InCharge financial distress/financial } \\
\text { well-being scale: Development, administration, and score } \\
\text { interpretation. Financial Counseling and Planning, 17(1), 34-50. }\end{array}$ & 164 \\
\hline 2 & $\begin{array}{l}\text { Mandell, L., \& Klein, L. S. (2009). The impact of financial literacy } \\
\text { education on subsequent financial behavior. Journal of Financial } \\
\text { Counseling and Planning, 20(1), 15-24. }\end{array}$ & 133 \\
\hline 3 & $\begin{array}{l}\text { Baktelsmit, V. L., \& Bernaskek, A. (1996). Why do women invest } \\
\text { differently than men? Financial Counseling and Planning, 7, 1-10. }\end{array}$ & 130 \\
\hline 4 & $\begin{array}{l}\text { Sung, J., \& Hanna, S. (1996). Factors related to risk tolerance. } \\
\text { Financial Counseling and Planning. 7, 11-19. }\end{array}$ & 114 \\
\hline 5 & $\begin{array}{l}\text { Montalto, C. P., \& Sung, J., (1996). Multiple imputation in the } \\
1992 \text { Survey of Consumer Finances. Financial Counseling and } \\
\text { Planning, 7, 133-141. }\end{array}$ & 109 \\
\hline 6 & $\begin{array}{l}\text { Robb, C. A., \& Woodyard, A. S. (2011). Financial knowledge and } \\
\text { best practice behavior. Journal of Financial Counseling and } \\
\text { Planning. 22(1), 60-70. }\end{array}$ & 96 \\
\hline 7 & $\begin{array}{l}\text { Wang, H., \& Hanna, S. (1997). Does risk tolerance decrease with } \\
\text { age? Financial Counseling and Planning, } 8(2), 27-32 .\end{array}$ & 89 \\
\hline 8 & $\begin{array}{l}\text { Edwards, E. A. (1993). Development of a new scale for measuring } \\
\text { compulsive buying behavior. Financial Counseling and Planning, } \\
\text { 4, 67-85. }\end{array}$ & 88 \\
\hline 9 & $\begin{array}{l}\text { Danes, S. M. (1994). Parental perceptions of children's financial } \\
\text { socialization. Financial Counseling and Planning, 5, 127-149 }\end{array}$ & 87 \\
\hline 10 & $\begin{array}{l}\text { Danes, S. N., \& Haberman, H. R. (2007). Teen financial } \\
\text { knowledge, self-efficacy and behavior: A gendered view. Financial } \\
\text { Planning and Counseling, 18(2), 48-60. }\end{array}$ & 84 \\
\hline
\end{tabular}

Source: Scopus, retrieved on February 2, 2020.

Etkin, 2020). For more information about the indexing of $J F C P$, also see Kelley, Lawrence, and Villere (2013) and Mason, Izenstark, and Xiao (2017).

\section{Journal Services}

\section{Author Services}

After the journal was published by Springer, an online submission system has been used that is convenient for authors to submit and monitor submission statuses. The publisher also maintains a journal website and posts recent papers and connects them to several helpful social media tools such as Kudos to help authors promote their papers. The publisher website also provides helpful features such as "Share," "Alert," "Most Cited," and so forth. (https://connect.springerpub.com/content/sgrjfcp). AFCPE staff have helped promote $J F C P$ papers by giving online research webinars and issuing social media posts. AFCPE also sponsors the outstanding research journal award and gives awards annually to a paper that is nominated by a nominating committee composed of the last year's winner and four editorial board members and then voted on by the entire editorial board members. The awarding paper and author information is posted on the AFCPE website. The JFCP editorial office has also helped distribute journal information through the Consumer listserv and other listservs and post recent published papers to the public.

\section{Readers and Member Services}

Papers in most older issues are available for readers that can be found on the AFCPE website. AFCPE also provides special benefits for its members to have access to research published in $J F C P$ such as social media posts, Friday research posts, online research webinars, and annual symposium special sessions. For members who need continuing 
education credits, reading $J F C P$ papers and answering questions online can partially fulfill the requirements.

\section{Future Directions}

Starting in the fourth decade of $J F C P$, we will continue the efforts in two aspects: continue publishing cutting-edge, high-quality, original research papers and further disseminate published research to practitioners in consumer finance. To achieve the first goal, we will actively recruit quality papers from researchers in multidisciplines such as economics, business, consumer science, social work, psychology, sociology, education, and any related fields and work hard to ensure $J F C P$ is included in more top indexes such as SSCI. To achieve the second goal, we will continue working with the leaders and staff of AFCPE and Springer and take full advantage of information technology and social media, actively engaging in conversations between researchers and practitioners to make research results be more accessible and useful for their work to benefit consumer financial well-being.

\section{Reflections by Sherman D. Hanna, the Founding Editor of JFCP}

Since 1990, the challenge has been not only to have articles that would be of interest to practitioners and researchers, but also to have a journal that would be an attractive outlet to researchers. Challenging is hard, and an author must have considerable motivation to do the work and initial writing and make many revisions to produce a manuscript that has rigorous, original research that is communicated clearly. There are some practitioners who are willing to do that for fame or glory, but most of the writers of articles that have appeared in this journal are in academia. In universities, the term "publish or perish" was common 30 years ago, but the level of productivity expected has steadily increased, with numbers of journal articles published expected 30 years ago for promotion to full professor now at some research universities being insufficient for tenure. While this increase in the expectations has contributed to the enormous increase in manuscript submissions to research journals, there has also been an increasing expectation about the prestige of the journals one targets. These trends have added to the challenges faced by the editor, including efforts to obtain indexing, especially listing in SSCI. Editors have been making progress on indexing, which will be crucial to the continued success of the journal.

\section{References}

Etkin, A. (2020). JFCP information for 2019. Unpublished file.

Hanna, S. D. (1999). Ten years of financial counseling and planning.. Financial Counseling and Planning, 10(2), 2-4.

Ji, H., Hanna, S. D., Lawrence, F. C., \& Miller, R. (2010). Two decades of the journal of financial counseling and planning. Journal of Financial Counseling and Planning, 21(1). 3-13

Kelley, R., Lawrence, F. C., \& Villere, P. F. (2013). Increasing influence of the journal of financial counseling and planning: Documentation of indexing in prominent databases. Journal of Financial Counseling and Planning, 24(2). 3-4

Mason, I. M., Izenstark, A., \& Xiao, J. J. (2017). The expanding impact and reach of journal of financial counseling and planning. Journal of Financial Counseling and Planning, 28(1), 3-4. https://doi.org/10.1891/1052-3073.28.1.3

(2009). Ulrich's periodicals directory (47th ed.). New Providence, NJ: R.R. Bowker.

(2019). Ulrich's periodicals directory (57th ed.). New Providence, NJ: ProQuest. https://apastyle.apa. org/learn/faqs/cite-book-no-author

Disclosure. The authors have no relevant financial interest or affiliations with any commercial interests related to the subjects discussed within this article.

Acknowledgments. We thank Rebecca Wiggins, Rachael DeLeon, Sara Martin-Fuller, and other Association for Financial Counseling and Planning Education (AFCPE) leaders and staff for their able and prompt assistances for the Journal of Financial Counseling and Planning (JFCP) editorial office. We also thank Adam Etkin, Megan Larkin, Diana Osborne, and other Springer leaders and staff for providing continuing support for publishing $J F C P$ and marketing it worldwide. 